\title{
Theory and practice of integrated coal production and gas extraction
}

\author{
Liang Yuan ${ }^{1}$
}

Received: 5 March 2015/Revised: 1 April 2015/Accepted: 4 April 2015/Published online: 21 May 2015

(C) The Author(s) 2015. This article is published with open access at Springerlink.com

\begin{abstract}
The integrated extraction of coal and gas combines coal mining with gas capture. Taking into account the gas deposition and flow conditions in the Chinese coal basins, this paper describes the status of the theory and key technologies of this integrated extraction system, and presents its application and practice in the Shaqu, Zhongxing, Fenghuangshan and Pingmei mines. Areas for further improvements in future studies are discussed, focusing in particular on the fundamentals of the extraction system to make it greener, more scientific, and more advanced in both the exploitation and utilization of coal and the gas in coal.
\end{abstract}

Keywords Integrated coal production · Gas extraction · De-stress mining · Pillarless mining · Circular overlying zone

\section{Introduction}

Most coal mines in China extract coal from seams with low permeability and high gas content. Gas control in such mining seams is a worldwide problem and the associated techniques are not completely optimized. Gas outburst accidents frequently occur during mining of these seams, therefore the productivity is lower, and it is very difficult to achieve safe and efficient mining. The Huainan mining area is a typical example of these conditions, having low permeability, high gas content, and complex geological conditions. Since 2004, the mining depth in Huainan coal mines has reached 700-1000 m, all 15 mines are classified as being outburst-prone, and the coal seams are characterized by low permeability $(0.001 \mathrm{mD})$, high gas content $\left(12-36 \mathrm{~m}^{3} / \mathrm{t}\right.$ ), and high gas pressures (up to $6 \mathrm{MPa}$ ). Mining of these seams by conventional methods generates

Liang Yuan

yuanl-1960@sina.com

1 State Key Laboratory of Deep Coal Mining \& Environment Protection, Huainan Mining Group Co., Ltd., Huainan 232001, China many problems, including coal pillars left in the panels, high abutment stress in the protected seams, the risk of outbursts, high gas emissions from the first-mined seam, gas accumulation at the upper corner of the longwall working face, a large amount of roadway excavation in rocks and at great depths, and the high cost of gas control.

Integrated coal and gas production combines coal mining with gas capture. This is a typical model for the development of dual resources (coal and gas in coal mine). Mining activity leads to desorption and flow of gas in the coal and creates favorable conditions for gas drainage. Furthermore, coal mining and its associated ventilation systems provide operating space for gas extraction. Efficient drainage of gas reduces the gas concentration and amount at the working face, which can effectively prevent gas explosions and eliminate coal and gas outbursts, thereby promoting safer and more efficient coal mining (Fields 1973; Garcia and Cervik 1985; Hargraves and Martin 1993; Creedy et al. 2001; Cheng et al. 2004, 2006). In recent years, integrated coal production and gas extraction has been developed and promoted rapidly in China, Australia, and other coal-mining countries, and has been demonstrated to be an effective method for safe and efficient mining of coal seams with high gas content and low permeability (Xie et al. 2006; Yuan 2008a). 
This paper summarizes the fundamental theory and key technologies of integrated coal production and gas extraction in an effort to promote its wider application. Applications to four coal mines in China are also presented to showcase its applicability and effectiveness.

\section{Research status}

Integrated coal production and gas extraction must be considered as a system which involves the exploration and measurement of stress field redistribution, deformation and failure of coal and rock, gas pressure and permeability, and gas desorption and migration during the process of coal mining.

\subsection{Fundamental theory}

\subsubsection{Deformation and failure of overlying roof strata and overburden pressure}

Theories of a natural equilibrium arch, pressure arch, cantilever beam, prefabricated fissures, articulated rock, elastic foundation beam, and many other well-known hypotheses have been proposed. In China, the masonry-beam structure model, passing-stress rock beam structure model, and key-layer theory have been proposed (Qian and Liu 1984; Song 1988; Qian and Shi 2003).

\subsubsection{Crack distribution in the overlying strata}

To optimize the design of the bore for drainage of pressurerelieved gas from a mining area, detailed fracture distribution behaviors generated by mining have been developed by Chinese scholars. For example, the O-ring fracture (Qian and Xu 1998), the elliptical parabolic band (Li et al. 1999), and the annular ring fracture distributions (Yuan 2008b) have been investigated and proven.

\subsubsection{Gas relief caused by mining flow patterns}

Based on empirical data, two models of relieved gas emissions have been established in Germany (Noack 1998), as shown in Fig. 1. One model the relationship between the extent of gas emission and different roof and floor heights, while the other relates gas pressure to different heights of the roof and floor. Both models have been widely applied to forecast gas emission volumes from adjacent layers and evaluate gas drainage technologies. In addition, empirical models of gas emissions from adjacent layers in the typical high-gas mining areas of Yangquan and Huainan coal mines have been established (Cheng et al. 2004, 2006).

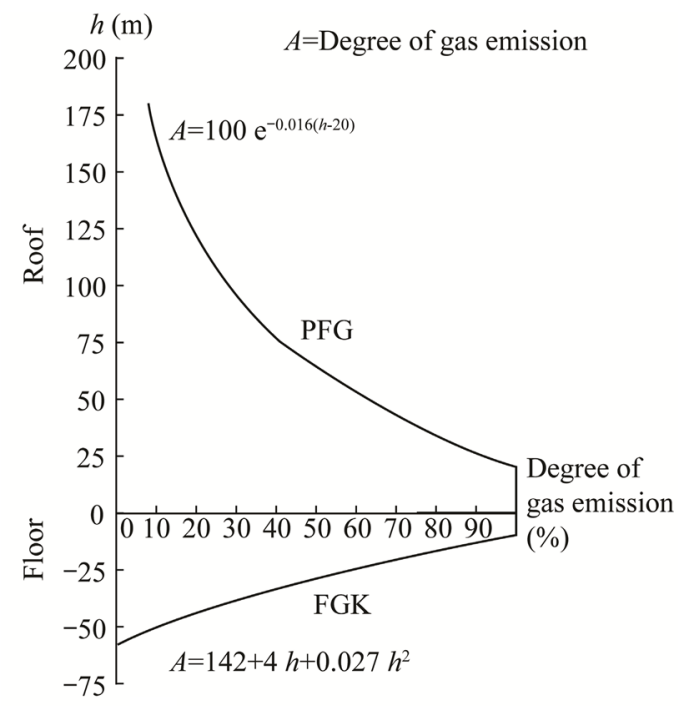

(a) Model of extent of gas emission

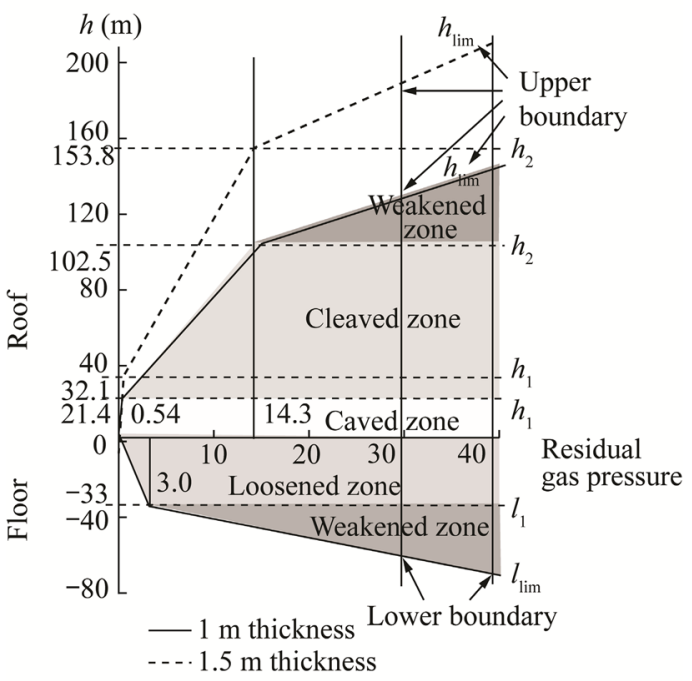

(b) Model of gas pressure

Fig. 1 Model of mining gas desorption emissions (Noack 1998). $P F G$ curve of degree of roof gas emissions; $F G K$ curve of degree of bottom gas emissions

\subsubsection{Variation of permeability and flow of relieved gas}

The relationship between stress distribution and permeability in the front of the working face and the surrounding goaf rock was analyzed. The permeability coefficient reduces as a function of the abutment pressure of the working face, while the permeability sharply increases in the gob with the transfer of mining-induced stress and then reduces again as the mining stress is removed. However, the permeability in the surrounding rock after compaction is still much larger than the original permeability. Variation of rock permeability was also studied by Palchik (2005), Unver and Yasitli (2005), and Usanov et al. (2014). Permeability distribution of the overlying relief gob seam 
along the advancing direction of the working face was analyzed by dividing it into three stages: initially increasing permeability and flow by pressure relief, followed by high permeability and flow by continued relief, and then reducing permeability and flow by pressure recovery $(\mathrm{Yu}$ 1984).

\subsection{Technical practice}

Gas extraction can be carried out before, during, and after mining. In countries such as the US or Australia, coal seams have higher permeability and occur at shallower depths (Fields 1973; Hargraves and Martin 1993; Steven et al. 2007). The main methods of gas extraction include pre-extraction by vertical wells (Garcia and Cervik 1985) and long ground directional drilling or bedding drilling. In recent years, coal bed methane development has gradually achieved a certain economy of scale. Gas extraction during and after mining is generally applied to low permeability coal seams by methods such as drilling through the coal seam, horizontal roof drilling, gob area wells, and special gas extraction tunnels (Noack et al. 1995; USEPA 1998, 1999). Drilling through coal seams and horizontal roof drilling are widely used in China and other countries, and gob area wells are widely used in countries with shallower coal depths, such as the US and Australia (Creedy et al. 2001; Michael 2007). In recent years, long ground directional drilling has become a new trend, and has been successfully applied in the US and Australia (Fig. 2). Coal mine methane extraction by directional drilling from the

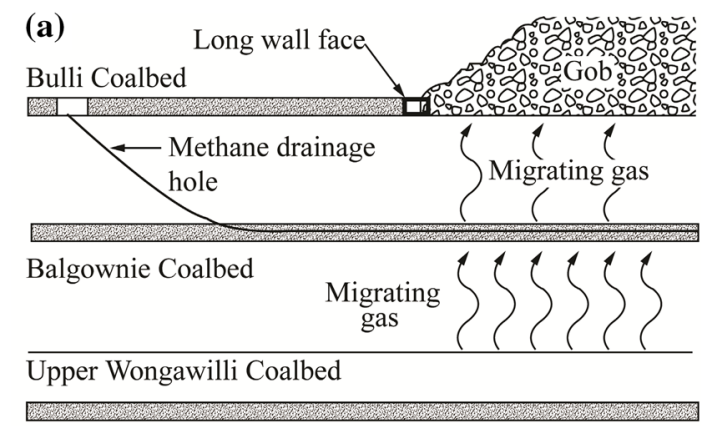

Lower Wongawilli Coalbed

(b)

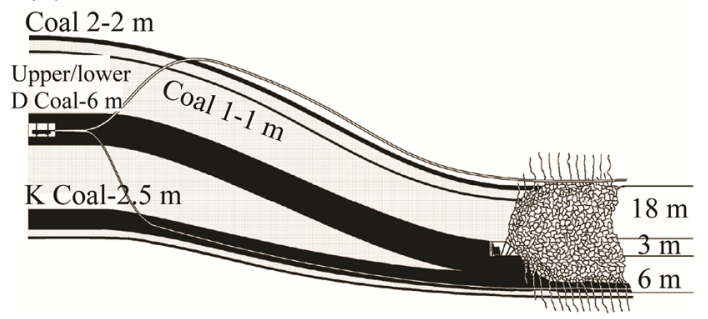

Fig. 2 Gas extraction by long ground directional drilling in the US and Australia ground into the coal seam has been applied in Australia, and advanced navigation systems for directional drilling have been developed. In China, techniques for gas extraction have been developed for conditions when pressure relief has been extended at a coal mine, such as in the Huainan, Yangquan, and Huaibei groups. Simultaneous extraction coal and gas by roadway retention and borehole drilling has been successfully implemented at Huainan coal mines.

\section{Technique of integrated coal production and gas extraction}

\subsection{Principles}

The principle of integrated coal production and gas extraction follows a sequence of phenomena. Following mining-induced failure and the consequent movement of surrounding rocks, the gas desorbs from the broken coal seams and becomes free-flowing, and is thereby able to move into fractures and accumulate in the coal and rock strata. This accumulated gas is extracted by gas drainage boreholes and/or tunnels concurrently with the mining of the coal seams. Figure 3 illustrates this principle.

By integrating coal production with gas extraction, coal seam gas becomes a useful resource. Advantage is taken of the effect of strata movement on gas pressure-relief and flow during the coal mining process to establish a single production system for simultaneous coal and gas extraction. By including gas drainage as part of the regular coal mining process, the traditional single coal resource mining pattern is transformed into an integrated production facility for both coal and gas.

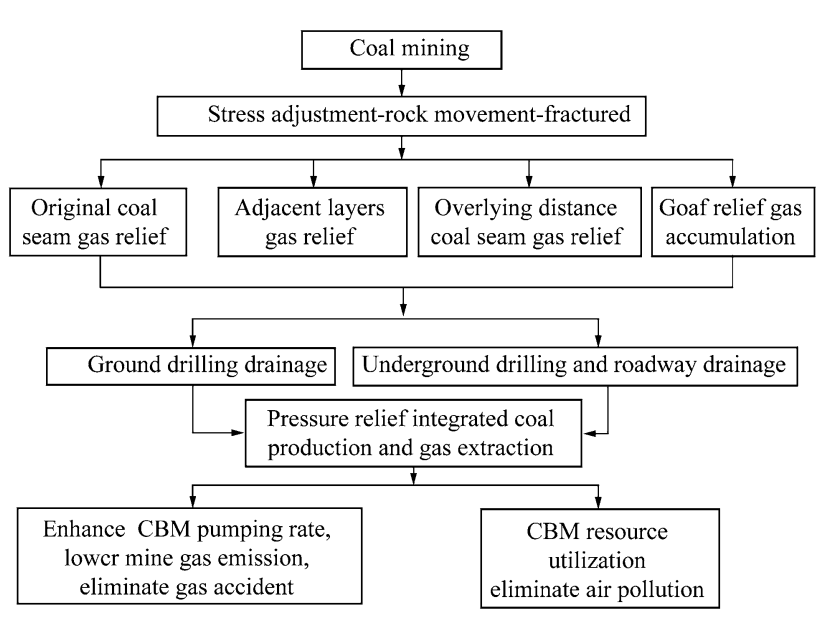

Fig. 3 Principle of integrated coal production and gas extraction 


\subsection{Theoretical foundations}

\subsubsection{The annular-shaped overlying zone theory}

The "annular-shaped overlying zone" theory has been proposed. The stress-relief coefficient of the overlying strata is obtained from numerical simulation results (Yuan et al. 2011a). The overlying zone can be considered an "annular-shaped fractured zone", which is located at a certain height above the goaf and has a particular width and extends upward at a particular angle. The zone has the following characteristics: (i) it can be divided into three sections along the strike, i.e., front, center, and rear. The front section is adjacent to the working face and runs through the working face in the direction of dip, and is the main region where gas desorption and emission occur. The central section connects the front and rear sections along two mining boundaries, and forms channels between these sections to allow large-scale gas flow. The rear section is near the cut and is smaller than the front section in size; (ii) the overlying annular-shaped fracture zone extends upward at a certain angle in the dip section, and the extension angles of the outward and inward boundaries are different; (iii) the overlying annular-shaped fracture zone is located in the strike section above the goaf at particular intervals and extends upward at a particular angle. The front range is larger than the rear range.

\subsubsection{Three-band structure in stress-relief layer}

The distribution and evolution of three bands in the stressrelief layers due to mining of the first seam have been clearly identified. These provide for the occurrence of desorption and formation of flow channels of gas in gasenriched regions. In the process of mining a working face without a pillar, the front abutment stress region is located 0-30 $\mathrm{m}$ ahead of the working face and the concentration factor is about 2-3. The stable stress-relief region is located $300-500 \mathrm{~m}$ ahead of the working face in the advancing direction, the fracture development area is 0-50 $\mathrm{m}$ behind the working face of the first-mined seam, the active strata movement region is some 50-500 $\mathrm{m}$ behind the working face, and the attenuation region is more than $500 \mathrm{~m}$ behind the working face developed toward the goaf in the form of a wedge (Yuan 2008a).

\subsubsection{Gas drainage by stress relief}

Technical principles for enhancing gas drainage by stress relief have been proposed. Mining-induced stress, gas pressure and permeability, strata movement, and fracture evolution behavior have been investigated. A linear relationship between gas pressure and stress and a negative exponential relationship between permeability and stress have been demonstrated. Additionally, mining of the first seam can induce expansionary deformation, stress relief, and permeability enhancement of neighboring coal seams (Yuan 2008b).

\subsection{Key Technologies}

\subsubsection{Excavation of a special roadway for gas drainage}

A special roadway should be excavated in the de-stressed and fractured region formed in the first or protective seam for gas drainage. This technology has been developed to target the gas-rich zones in this region. This gas-rich region, which has a width of $0-30 \mathrm{~m}$ and height of $8-25 \mathrm{~m}$, is located in the annular-shaped fractured zone above the two roadways of the working face (Yuan 2008c).

This technology has been further developed to extract desorbed gas from overlying de-stressed coal seams that are spaced some distance from the first-mined seam. Once the first (protective) seam is mined, the range of the destressed region develops upward at a strike fracture angle of $80^{\circ}-85^{\circ}$ and the de-stressed layer is located $10-150 \mathrm{~m}$ above the protective seam (Yuan 2009a).

This technology has also been applied to extract desorbed gas from the underlying de-stressed protected coal seams. After the first seam is mined, the de-stressed range develops downward at strike and dip fracture angles of $99^{\circ}-100^{\circ}$ and $102^{\circ}-110^{\circ}$, respectively, and the de-stressed layer is located 15-100 m below the protective seam (Yuan 2009b).

Ground well technology for gas drainage from destressed regions has been developed. This includes well construction and operating procedures. Technologies for controlling deformation of the surrounding roadway rocks in soft coal seams have also been developed. These include bolt-grouting support of soft rock roadways with high stress and controlled pre-stressing of fractured roofs with obviously inclined separation.

\subsubsection{Roadway controlling technologies in pillarless mining}

Technologies for roadways include support with strengthened bolting, meshing, and grout injection, a self-moving shield for reinforced support in mining-perturbed roadways, and building of packing walls for retaining gob-side roadways. Other key technologies include the development of materials capable of withstanding high loading for the packing walls, a modular shield for constructing the packing walls, and pre-fracturing of the working face roof for de-stressing. The initial and periodic caving intervals can be reduced by weakening the roof strength using 
advanced deep-hole pre-splitting blasting. An initiative for support roofing with high stiffness has been proposed, which emphasizes the "three high" bolting system, i.e., high strength, high pretension, and high stiffness of bolts (Yuan et al. 2011a, b).

\subsubsection{Gas drainage by boreholes drilled in the retained roadway}

A new concept for safe and efficient gas extraction has been proposed based on pillarless mining with a Y-shaped ventilation system. Boreholes in the retained roadways are drilled into the de-stressed and gas-rich zones in the overlying and underlying regions to extract gas (Yuan 2010).

\section{Main achievements}

\subsection{Overlying annular fractured zone}

Three-dimensional computational fluid dynamics modeling of a typical mining panel has revealed the existence of an overlying annular-shaped fractured zone in which gas-rich sections are located. The basic geometric features for highly efficient gas drainage are fully understood. A zone with a certain width locates at a particular height above the goaf and extends along the vertical direction at a particular angle, as shown in Fig. 4.

The basic criteria for identifying this zone in multiple coal seams with low permeability are as follows:

(1) High gas desorption rate: Based on specific coal seam conditions, the effective stress reduction factors can be determined when gas desorbs significantly, and the zones in which high gas desorption occurs are identified according to the overlying strata stressrelief model.

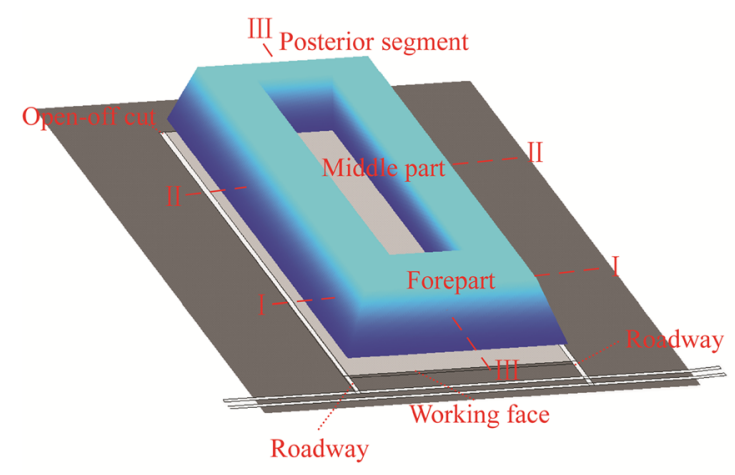

(2) High permeability: High permeability is used to identify zones where mining-induced fractures are highly developed and compaction starts to occur. Regions with high permeability are determined using the overlying permeability distribution model. The upper boundary of the range for effective gas drainage does not exceed the upper boundary of the horizontal high permeability zone.

(3) High concentration of gas extracted: The minimum purity requirement of the gas extracted is determined and the range of gas purities is determined by applying the basic laws of gas dynamic flow.

Based on the above, the regions of highly efficient gas extraction from multiple coal seams can be determined.

\subsection{De-stressed extraction of coal and gas}

Gas drainage is implemented by placing roadways and/or boreholes in the de-stressed and/or fractured zones formed by mining of the first (protective) seam in multiple coal seams. A sketch of the gas drainage system is shown in Fig. 5.

\subsection{Pillarless extraction of coal and gas}

With the use of a Y-type ventilation system, the coal in front of the working face in the first seam is mined, while gas from both the protective and protected seams is extracted through boreholes drilled in the retained roadways. In this way, integrated coal production and gas extraction is achieved. The extracted gas is separated into high- and low-purity components, and transported to the surface for use in electric power plants and domestic cooking and heating, respectively.

Depending on the location of the gas-rich zones, boreholes in the retained roadway can be drilled up- and/or

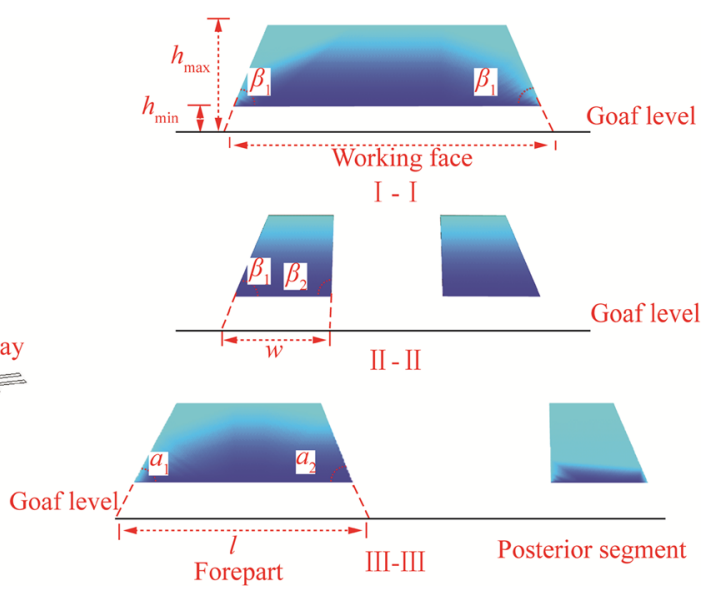

Fig. 4 Annular-shaped overlying zone 


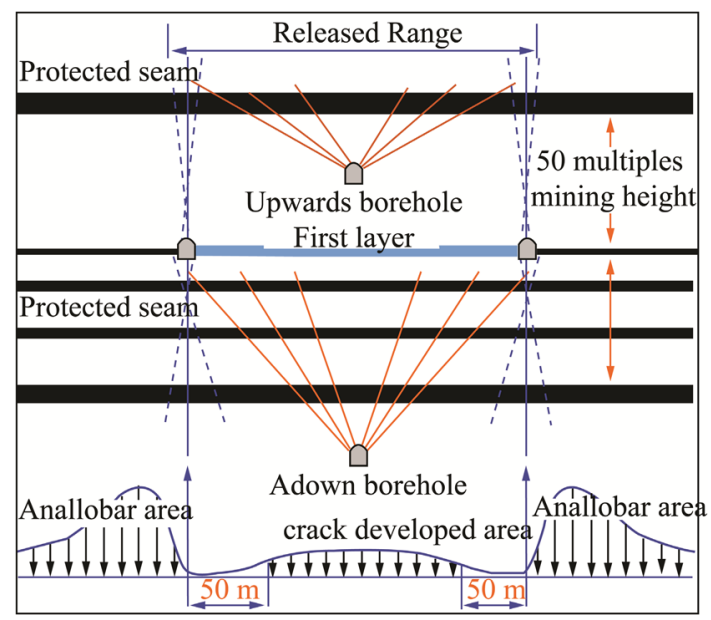

Fig. 5 De-stressed gas drainage system

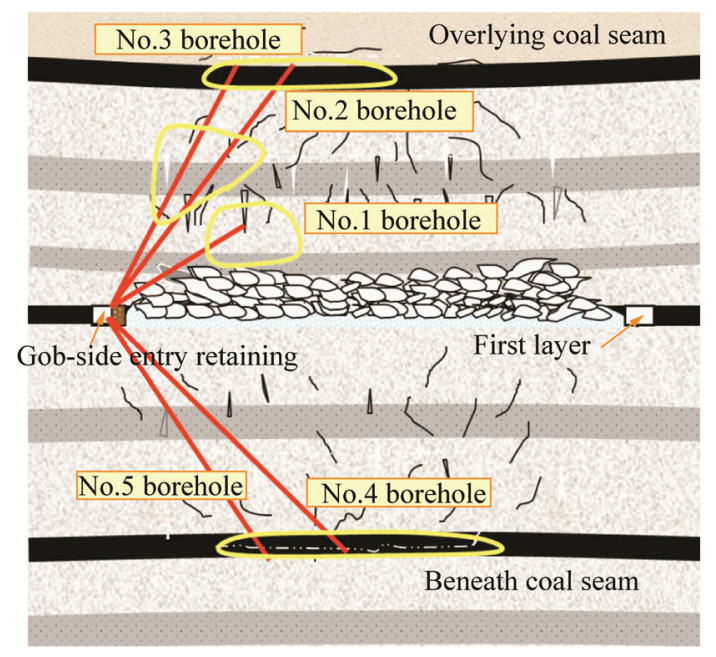

Fig. 6 Pillarless extraction of coal and gas

downward to target the gas-rich zones in both overlying and underlying strata. The pillarless extraction of coal and gas is schematically shown in Fig. 6.

\subsection{Innovative research methods}

A large-scale physical model has been developed for fundamental research into integrated coal production and gas extraction, as shown in Fig. 7. The main components of the model include an outburst simulation instrument, an excavation system, a data monitoring and recording system, a dynamic data-analyzing system, and a virtual early-warning system. The geometric dimensions of the model are $3000 \mathrm{~mm} \times 3500 \mathrm{~mm} \times 2000 \mathrm{~mm}$ (length $\times$ width $\times$ height) and it can be easily transported. Largescale geomechanical tests can be implemented with advanced monitoring systems to study integrated coal and gas production in seams with low permeability. Development

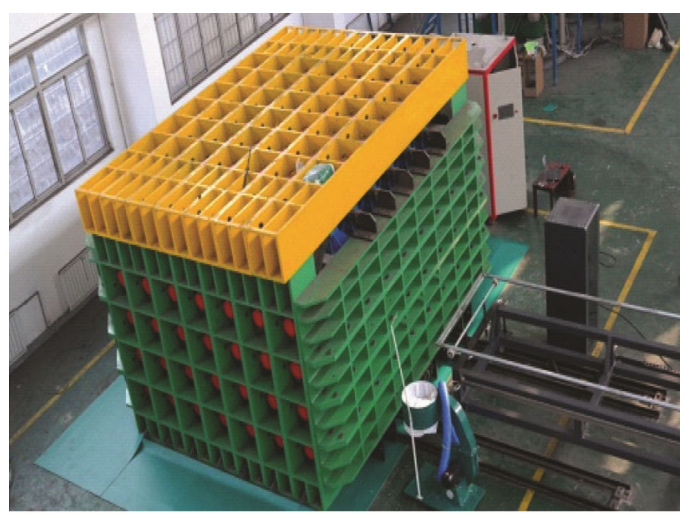

(a) 3D model

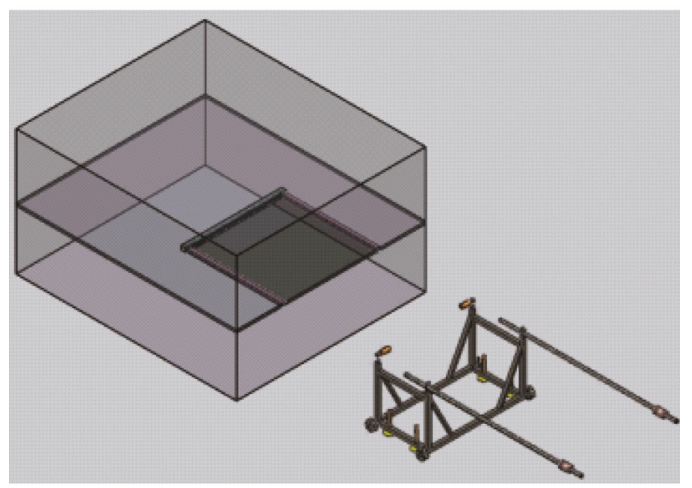

(b) Excavation system

Fig. 7 Large-scale physical model for simulation of coal and gas extraction

and evolution of the stress and fracture zones in a retained roadway and in overlying or underlying seams with pillarless mining can be investigated under various stress, geological, and excavation conditions.

\section{Operating practice}

The core ideas relating to the integrated extraction of coal and gas are consistent with scientific, efficient, and practical engineering principles. Coal resources in China differ vastly in the nature of their deposition; the theoretical and technological innovations with respect to integrated extraction of coal and gas take different deposition conditions and different mining methods into account.

Integrated extraction of coal and gas originated in the Huainan coal mining group. Huainan was once one of the areas with the most serious gas outburst and explosion hazards in the Chinese coal industry. Because of the high gas content and low permeability of coal seams in Huainan, innovative methods were developed to enhance seam permeability to resolve these issues. Coal permeability is improved by mining-induced de-stressing, thereby enabling the integrated extraction of coal and gas. These 
technological developments have completely prevented the reoccurrence of gas explosion accidents and greatly improved coal productivity and gas extraction efficiency. All coal mines in Huainan now simultaneously extract coal and gas. Annual gas extraction from the mines is about $500 \mathrm{Mm}^{3}$.

The successful demonstration of this technology in Huainan played an important role in resolving gas control in other gas-containing Chinese coal mines. It has been applied in Shanxi, Henan, Shanxi, Heilongjiang, Hebei, Xinjiang, and other major coal-producing provinces. Coal production from mines using this technology is some 21 billion tons.

As a first example, the geological conditions of the Shaqu coal mine in Shanxi province are very complex and it is one of the highest gas-emitting mines in China. The gas content is $29 \mathrm{~m}^{3} / \mathrm{t}$, the pressure is up to $2.4 \mathrm{MPa}$, and the absolute gas gushing quantity is $473 \mathrm{~m}^{3} / \mathrm{min}$. In 2008 , the gas concentration exceeded the statutory limit in 3635 incidents, in each incident exceeding a concentration of $2.5 \%$ (Yuan 2008c). In the 6 years prior to 2012, coal production was about $200 \mathrm{Mt}$ (design capacity was $300 \mathrm{Mt}$ ), and production capacity was seriously restricted by this gas problem. Integrated extraction of coal and gas was implemented in 2011, with comprehensive gas-control measures, such as protective mining, progressive drainage, Y-type ventilation, expansion of the gas extraction system, underground gas drainage from retained roadways, surface well drainage, and gas use. By the end of 2012, the number of gas incidents had dropped to five, and none occurred in 2013.

The second example is the successful implementation of integrated coal production and gas extraction with pillarless mining in the 1205 working face of the Zhongxing coal mine, Fenxi Coal Mining Group. This mine comprises typical "three soft" multiple coal seams with close intervals and composite fragmented thick roof conditions. Field observations indicate that the retained roadway (crosssectional area of $12 \mathrm{~m}^{2}$ ) is well maintained and its crosssectional shrinkage is only $11.11 \%$. The average gas extraction from the working face is $43.17 \%$ and the average gas concentration at the tail entry is $0.33 \%$, indicating of the effective gas extraction of the mine.

A third example is the successful application of integrated coal production and gas extraction at the working face 154,307 (with thick and hard roof conditions) of the Fenghuangshan coal mine, Jincheng Coal Group. The overlying seam of the mine was outburst-prone and the accumulated gas needed to be drained. Gas drainage is carried out through boreholes in the retained roadway of the working face, arranged in the overlying seam and supplemented by surface drainage wells. Field observations show that the number of gas incidents dropped by $88 \%$ and the risk of outbursts in the overlying seam was eliminated.

As a final example, the mining depth of the working face in the Henan Pingdingshan Coal Group was $1100 \mathrm{~m}$ and the retained roadway was under conditions of high stress with a thick, hard roof. The roadway floor seriously heaved, and the abutment stress resulting from sudden breaking of a large area of overhanging roof in the working face was very high. Various measures were taken to resolve these issues. Roof stress was relieved by pre-splitting explosion with roof long boreholes and the "three high and one strong" support technique was used to control roadway stability. In addition, a Y-shaped ventilation system, gas drainage boreholes arranged in the de-stressed seams, development of a new high-strength material for the packing wall, and the use of a mechanized filling technique to build the packing wall were also implemented.

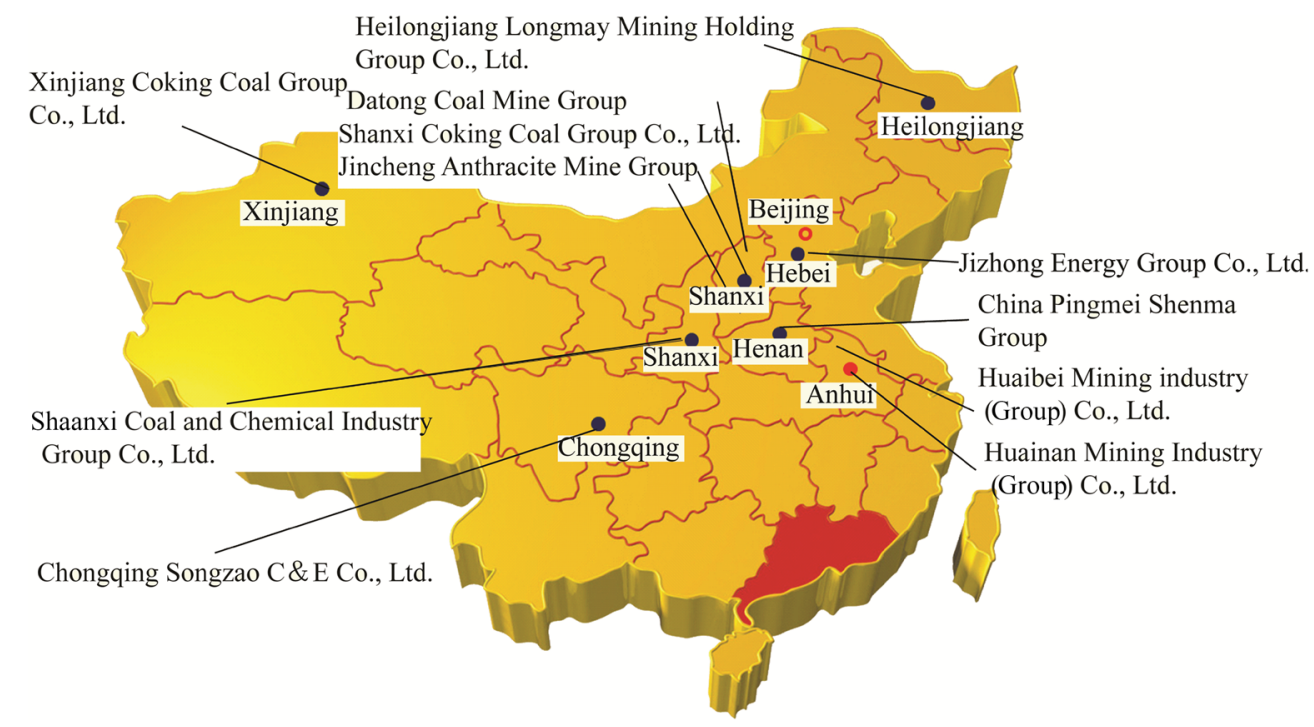

Fig. 8 Chinese coal mines practicing integrated extraction of coal and gas 
These achievements provide robust technical support for the extraction of deep coal and gas resources. Figure 8 shows the Chinese coal mines in which integrated extraction of coal and gas is applied.

\section{Conclusions}

China has rich coal resources. With increasing energy consumption and a greater demand for a cleaner environment, integrated coal production and gas extraction will play an increasingly important role. As demonstrated over the last 10 years in Huainan and other mines with similar conditions, integrated production of coal and gas is probably the only way to make coal mining greener and more scientific. The main theoretical and technological achievements for this technology are summarized as follows:

(1) Dynamic evolution and distribution of mininginduced stress, fracture, and gas flow fields in mining multiple seams of high gas content and low permeability;

(2) Identification of a circular overlying zone for efficient gas extraction;

(3) Excavation of overlying and underlying gas drainage roadways in de-stressed fractured zones induced by mining the first (protective) seam;

(4) Pillar mining with a retained roadway and Y-type ventilation;

(5) Gas drainage via boreholes drilled in the retained roadway into gas-rich zones in overlying and underlying strata.

Implementation of integrated coal and gas production can not only secure energy supply for sustainable economic development in China, but also enhances the scientific and technological level of China's coal mining industry. Further theoretical and technological research is required to make coal mining greener, more scientific, and more efficient.

Open Access This article is distributed under the terms of the Creative Commons Attribution 4.0 International License (http:// creativecommons.org/licenses/by/4.0/), which permits unrestricted use, distribution, and reproduction in any medium, provided you give appropriate credit to the original author(s) and the source, provide a link to the Creative Commons license, and indicate if changes were made.

\section{References}

Cheng YP, Yu QX, Yuan L (2004) Experimental research on coal and gas safely and efficiently remote relief exploitation. J China Univ Mining Technol 33(2):132-136
Cheng YP, Zhou DY, Yu QX (2006) Research on protection layer relief gas drainage and emission laws. J Mining Saf Eng 23(1):12-18

Creedy DP, Garner K, Holloway S et al (2001) A review of the worldwide status of coalbed methane extraction and utilisation. Report No. COAL R210, DTI/Pub URN 01/1040

Fields HH (1973) Degasfication through vertical shafts. In: Methane Control in Eastern U.S. oal ines. United States Department of Interior \& Bureau of Mines Information Circular IC 8621, 25-38

Garcia F, Cervik J (1985) Methane control on longwalls with corssmeasure boreholes. Report of Investigations 8985, United States Department of the Interior

Hargraves AJ, Martin CH (1993) Australasian coal mining practice. The Australasian Institute of Mining and Metallurgy

Li SG, Shi PW, Qian MG (1999) Research on overburden elliptical parabolic crack with dynamic distribution. Ground Press Strata Control 3-4:44-46

Michael B (2007) High performance longwall mining in deep and methane rich coal deposits in Germany taking into account methods and technologies for controlling the estimated gas liberation. In: Proceeding of 2007 China (Huainan) international symposium on coal gas control technology, Huainan, China, $57-75$

Noack K (1998) Control of gas emissions in underground coal mines. Int J Coal Geol 35:57-82

Noack K, Koppe U, Kunz E (1995) Control of high gas emissions in underground coal mines. In: International symposium workshop on Management and Control of High Gas Emissions and Outbursts in Underground Coal Mines. 20-24 March, Wollongong, Australia, 16-24

Palchik V (2005) Localization of mining-induced horizontal fractures along rock layer interfaces in overburden: field measurements and prediction. Environ Geol 48:68-80

Qian MG, Liu XC (1984) Mine pressure and control. China Coal Industry Publishing House, Beijing

Qian MG, Shi PW (2003) Mining pressure and strata control. China University of Mining \& Technology Press, Xuzhou

Qian MG, Xu JL (1998) Research on overburden fracture distribution "O" ring features. J China Coal Soc 23(5):466-469

Song ZQ (1988) Practical mine pressure. China University of Mining \& Technology Press, Xuzhou

Steven S, Bruce A, Crosdale P et al (2007) Coal petrology and coal seam gas contents of the Walloon Subgroup-Surat Basin, Queensland, Australia. Int J Coal Geol 70:209-222

Unver B, Yasitli EE (2005) Modelling of strata movement with a special reference to caving mechanism in thick seam coal mining. Int J Coal Geol 66(4):227-252

Usanov SV, Mel'nik VV, Zamyatin AL (2014) Monitoring rock mass transformation under induced movements. J Min Sci 49(6):913-918

USEPA (1998) Coalbed methane recovery and electric power generation project-opportunity at the Wesola Mine Myslowice, Poland

USEPA (1999) White paper: guidebook on coalbed methane drainage for underground coal mines

Xie HP, Peng S, He M (2006) Deep mining basic theory and engineering practice. Science Press, Beijing

Yu QX (1984) Gas prevention in coalmine. China University of Mining \& Technology Press, Xuzhou

Yuan L (2008a) Key technique of safe mining in low permeability and methane-rich seam group. Chin J Rock Mech Eng 27(7):1370-1379

Yuan L (2008b) Theory and practice of integrated pillarless coal production and methane extraction in multi-seams of low permeability. China Coal Industry Publishing House, Beijing 
Yuan L (2008c) Gas distribution of the mined-out side and extraction technology of first mined key seam relief-mining in gassy multiseams of low permeability. J China Coal Soc 33(12):1362-1367

Yuan L (2009a) Theory of pressure-relieved gas extraction and technique system of integrated coal production and gas extraction. J China Coal Soc 34(1):1-8

Yuan L (2009b) Theory and practice of integrated pillarless coal production and methane extraction in multiseams of low permeability. Eng Sci 11(5):72-80
Yuan L (2010) Concept of gas control and simultaneous extraction of coal and gas. China Coal 6:5-12

Yuan L, Guo H, Shen BT, Qu QB, Xue JH (2011a) Circular overlying zone at longwall panel for efficient methane capture of mutiple coal seams with low permeability. J China Coal Soc 36(3):357-365

Yuan L, Xue JH, Liu QS, Liu B (2011b) Surrounding rock stability control theory and support technique in deep rock roadway for coal mine. J China Coal Soc 36(4):535-543 